Rui S. D. Alão *

\title{
Sobre a complexidade dos problemas contemporâneos de design
}

Rui S. D. Alão é designer digital, sócio do estúdio Carambola Digital, arquiteto pela FAU USP, especialista e mestre em Design pela Universidade Anhembi Morumbi (UAM) e doutor em Arquitetura e Urbanismo pela FAU-USP. Professor do Centro Universitário Belas Artes e da Universidade Anhembi Morumbi. Participa como pesquisador do MediaLab (UAM) e do Grupo de Pesquisa Design e Convergência (Belas Artes). <ruialao@gmail.com >

ORCID: 0000-0002-2182-6608
Resumo Este artigo investiga algumas características dos problemas contemporâneos de design. Argumentamos que a complexidade destes problemas cresceu muito a ponto de colocar em xeque os métodos tradicionais de projeto, tanto em função da instabilidade das paisagens de solução quanto em função da mobilidade dos sistemas nos quais estão imersos. Como principal contribuição, apontamos para a criação de comunidades mistas de designers e usuários e sugerimos que novos processos metodológicos sejam concebidos, prototipados e testados para dar conta de enfrentar problemas de design de alta complexidade.

Palavras chave Metodologia de design, Complexidade, Colaboração, Teoria dos sistemas, Metadesign. 


\section{On the complexity of contemporary design problems}

Abstract This article investigates some characteristics of contemporary design problems. We argue that the complexity of these problems has grown to the point of jeopardizing traditional design methods, mainly due to instability of the solution landscapes as the mobility of the systems in which they are immerse. As a main contribution, we recommend the creation of designers and users mixed communities and suggest that newer methodological processes be conceived, prototyped and tested to cope with high complexity design problems

Keywords Design methodology, Complexity, Collaboration, Systems theory, Metadesign.

\section{Sobre la complejidad de los problemas de diseño contemporáneo}

Resumen Este artículo investiga algunas de las características de los problemas de diseño contemporáneos. Argumentamos que la complejidad de estos problemas ha crecido hasta el punto de cuestionar los métodos de diseño tradicionales, tanto por la inestabilidad de los paisajes de soluciones como por la movilidad de los sistemas en los que están inmersos. Como principal contribución, buscamos crear comunidades mixtas de diseñadores y usuarios, y sugerimos que se conciban, prototipan y prueben nuevos procesos metodológicos para hacer frente a problemas de diseño de alta complejidad.

Palabras clave Metodología de diseño, Complejidad, Colaboración, Teoría de sistemas, Metadiseño. 


\section{Introdução}

Os problemas atuais do campo do design são mais complexos que os de 40 ou 50 anos atrás e estes mais complicados que os de décadas anteriores. Esta progressão, longe de ser uma novidade, já foi várias vezes mencionada por diferentes autores e expressada através de diferentes pontos de vista, como veremos a seguir. No entanto, nos acostumamos a utilizar os mesmos métodos para solução destes problemas. Foram poucas as propostas metodológicas que tiveram como ponto de partida este aumento de complexidade e há pouca compreensão de como as mudanças nos níveis de complexidade de nosso cotidiano afetam estes problemas.

Aqui pretendemos ponderar acerca dos motivos da necessidade de novos métodos para o campo do design e tentar esboçar alguns caminhos possíveis. Para isso, no entanto, vamos precisar estabelecer alguns conceitos a respeito do campo da complexidade, como os diferentes tipos de problemas e paisagens de solução, juntamente com os diferentes padrões de comportamento dos sistemas quanto à complexidade. Uma vez feito isso, vamos à discussão propriamente dita, ou seja, colocar a questão da complexidade numa perspectiva metodológica e histórica, a fim de encaminhar algumas questões próprias da área.

\section{Complexidade, cognição e projeto}

A vida humana se transformou radicalmente nos últimos 150 anos: de uma sociedade rural, onde cada indivíduo conhecia algumas dezenas de pessoas ao longo da vida, para uma sociedade urbana, internacional e interconectada, na qual conhecemos centenas ou milhares de pessoas, mesmo se contabilizarmos somente as conexões das redes sociais.

Também as possibilidades de deslocamento, de consumo, de aprendizado, de conexão de qualquer natureza cresceram muito e provavelmente vão continuar a crescer. Com o aumento das conexões e da interdependência entre estas partes, sejam elas indivíduos, empresas ou instituições, aumenta também a complexidade dos contextos para os quais projetamos. São contextos que não são só de grande complexidade, mas que frequentemente mudam de comportamento ao serem influenciados por outros contextos.

O biólogo austríaco Bertalanffy (2016), autor de uma das mais prestigiadas versões da teoria dos sistemas, estabelece que estes sistemas podem migrar de um estado de equilíbrio cíclico, onde há previsibilidade e grande estabilidade, para um estado de complexidade, onde os horizontes de previsibilidade se perdem justamente em função do aumento de conexões e da interdependência entre os agentes. Assim, dada a complexidade que observamos em nossos dias, é provável que estejamos nos deslocando, 
enquanto sociedade, de uma estrutura estável para uma instável sob vários pontos de vista. $O$ simples aumento de conexões se transforma em uma mudança qualitativa que faz com que comportamentos emergentes inesperados surjam espontaneamente no sistema e deixem de ser tão facilmente tratáveis.

\begin{abstract}
O significado da expressão um tanto mística "o todo é mais que a soma das partes" consiste simplesmente em que as características constitutivas não são explicáveis a partir das características das partes isoladas. As características do complexo, portanto, comparadas às dos elementos, parecem "novas" ou "emergentes". (...) Fisicamente, estes enunciados são triviais; mas podem tornar-se problemáticos e conduzir a concepções confusas em biologia, psicologia e sociologia somente por causa de uma interpretação errônea da concepção mecanicista, uma vez que existe a tendência para a resolução dos fenômenos em elementos independentes e cadeias causais, enquanto as inter-relações eram deixadas de lado (BERTALANFFY, 2016, p. 83).
\end{abstract}

Da mesma forma, nossa capacidade cognitiva também é desafiada na medida em que alguns problemas de grande complexidade são praticamente impenetráveis à nossa capacidade de gerar modelos mentais do que estamos tentando resolver. Vários autores de nossa área têm, igualmente, chegado a esta constatação.

O movimento Design Methods surgiu nos anos 1950 ao enquanto se percebia que indivíduos criativos trabalhando em isolamento não conseguiam mais resolver os problemas maiores e mais complexos que os aguardavam no período pós Segunda Guerra Mundial. Isto se refletiu no curriculum das instituições mais progressistas como a Hochschule für Gestaltung em Ulm, onde o design foi colocado ao lado de outras disciplinas como antropologia, sociologia, psicologia do comportamento, história e teoria cultural recente. (WOODHAM, 2006, p. 121) ${ }^{1}$

(...) a complexidade crescente de fatores envolvidos nos projetos de design não permite mais que o seu desenvolvimento se fundamente apenas na intuição ou na experiência adquirida. (CIPINIUK e PORTINARI, 2006)

Os escritos de teóricos do design defendem que o método tradicional do "projetar pelo desenho" (design by drawing) é muito simples para a crescente complexidade do mundo feito pelo homem. Essa crença é bastante ampla e não requer uma maior justificação (JONES, 1992, p. 27)² 
Imaginar que qualquer grupo fechado poderia resolver os problemas que nós enfrentamos hoje é loucura (MAU, 2004, p. 91) ${ }^{3}$

Não estamos acostumados a lidar com estes tipos de problemas pois o nosso comportamento de busca de soluções está preparado para outros tipos de desafios. Não é possível mais confiar a uma pessoa (ou a um punhado) um problema de difícil solução que esteja verdadeiramente imerso nas condicionantes interconectadas de nossa sociedade. Peter Miller, autor de Smart Swarm, que investiga as possibilidades do gerenciamento massivo através das tecnologias de rede, liga esta limitação à forma como evoluímos.

\footnotetext{
A intuição humana, que foi provavelmente modelada pela evolução biológica para lidar com um ambiente de caçadores e coletores, está mostrando os limites em um mundo cuja dinâmica se torna mais e mais complexa a cada minuto. (MILLER, 2011, p. 57) ${ }^{4}$
}

O problema, portanto, reside na impossibilidade de assimilação completa das condições e das interdependências contidas no cerne dos problemas contemporâneos. Esta limitação faz com que não consigamos sequer formar um modelo mental dos problemas mais complexos que enfrentamos. E sem conseguir formar este modelo, toda a esperança de um tratamento convencional destes problemas é perdida, pelo menos enquanto estivermos falando de soluções individuais ou de especialistas.

\section{Dançando sobre areia movediça}

Para ilustrar o que queremos dizer vamos tomar emprestado a metáfora usada pelo pesquisador Scott E. Page (2009), diretor do Centro para o Estudo de Sistemas Complexos da Universidade de Michigan, quando se refere a solução para tipos diferentes de problemas: a metáfora das paisagens.

Page afirma que existem vários tipos diferentes de problemas. Alguns são mapeáveis facilmente, outros nem tanto, e cada tipo de problema geraria um tipo diferente de mapa de solução. Nos eixos X e $\mathrm{Z}$ estariam combinações de variações das soluções, e no eixo Y estaria representada a adequação ou eficiência da solução. Alguns problemas fáceis de mapear, dariam origem a mapas igualmente previsíveis, enquanto outros problemas seriam representados por mapas mais acidentados.

Digamos, por exemplo, que queremos descobrir qual o tamanho de pá mais eficiente para se colocar carvão numa fornalha. Se usarmos uma pá muito pequena, ela pode ser leve e ágil, mas não vai acumular muito carvão, e o esforço do carvoeiro não será muito eficiente. Por outro lado, 
se for muito grande, pode acumular muito carvão, mas será provavelmente muito pesada e vai cansar o carvoeiro rapidamente. Assim, a pá ideal, que carrega uma boa quantidade de carvão e tem um peso razoável, é uma pá intermediária. Este problema gera como matriz de solução um gráfico com o formato de um monte. Sua representação tridimensional seria algo assim:

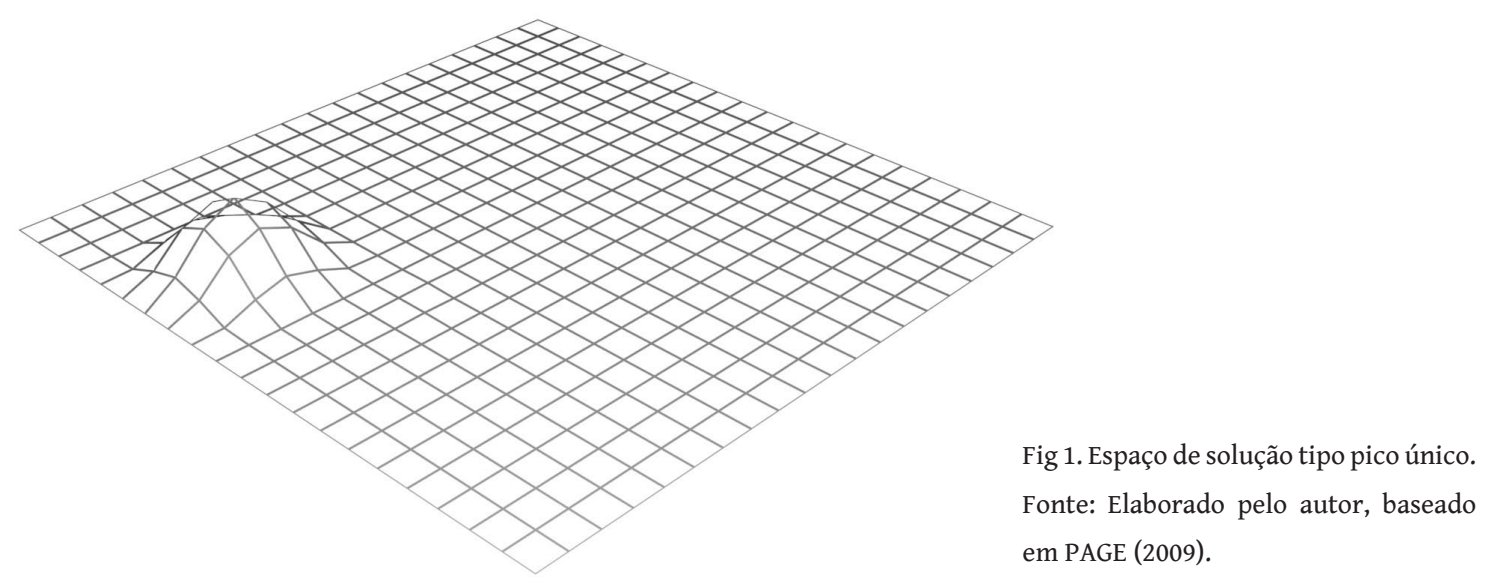

Outros problemas são mais complicados e formam, como matriz, uma cordilheira com vários montes e vales. Se pensarmos, por exemplo, em uma companhia aérea que deve fazer a sua programação de voos, na qual deve selecionar aeronaves, tripulação, origem e destino, horários, trocas de funcionários e outras tantas variáveis, uma vez levantada a demanda de passagens ou de carga, deve fazer um esforço razoável para racionalizar suas operações. Uma aeronave grande demais para uma certa tarefa desperdiça combustível; uma escala desnecessária desperdiça tempo e horas/homem; voos com poucos horários podem perder oportunidades de venda de passagens e assim por diante. O problema tem um bom número de variáveis e pode ser "resolvido" de várias formas. Ficamos então num jogo de ganha e perde, onde nenhuma das soluções é ideal para todos os aspectos, embora algumas sejam muito melhores do que outras. Poderíamos gerar uma matriz multidimensional na qual temos pontos melhores e piores. Neste caso, os vários montes representam soluções boas, e os vales, ruins. Mas apesar de existirem um vasto espaço a ser explorado, uma vez encontrado o pico mais alto, temos a solução ideal: o problema não muda, ele permanecerá onde está.

E existe outro tipo de problema, que resulta em uma paisagem ainda mais difícil de lidar do que a anterior. 


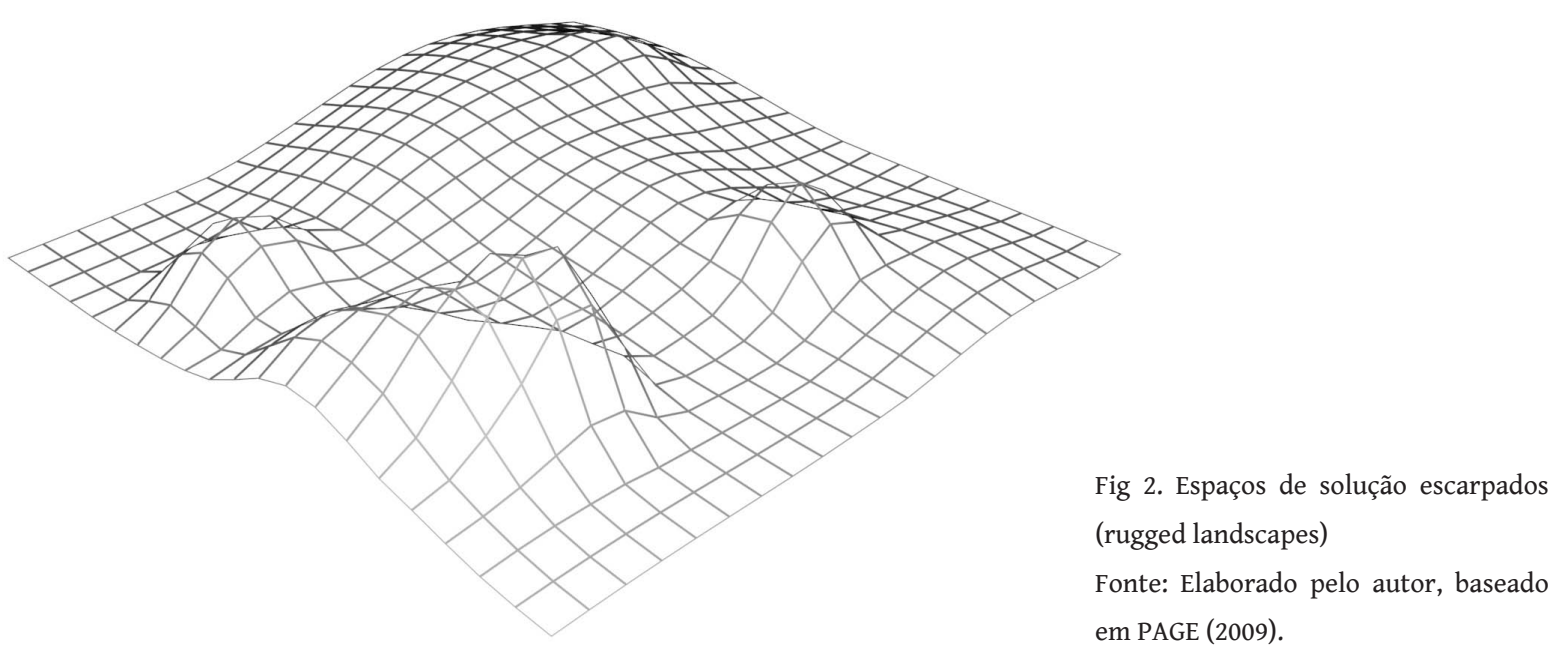

Se considerarmos o exemplo anterior, da companhia aérea, e incluirmos na proposição uma ou duas empresas concorrentes, teremos como resultado não uma paisagem mais escarpada ainda, mas uma paisagem de um relevo dançante, pois para cada solução encontrada pela nossa companhia hipotética, teríamos outras soluções tomadas nas mesas de conselheiros das companhias concorrentes. Para cada alteração que pudéssemos fazer, as concorrentes reagiriam e teríamos que novamente nos mover na paisagem, pois as condições para uma solução ótima seriam alteradas. Em resumo, o relevo seria movediço.

Neste caso, estamos finalmente falando de complexidade.

Enquanto tivermos muitas soluções possíveis, mas as condições nas quais trabalharmos forem fixas, podemos ter dificuldade em encontrar

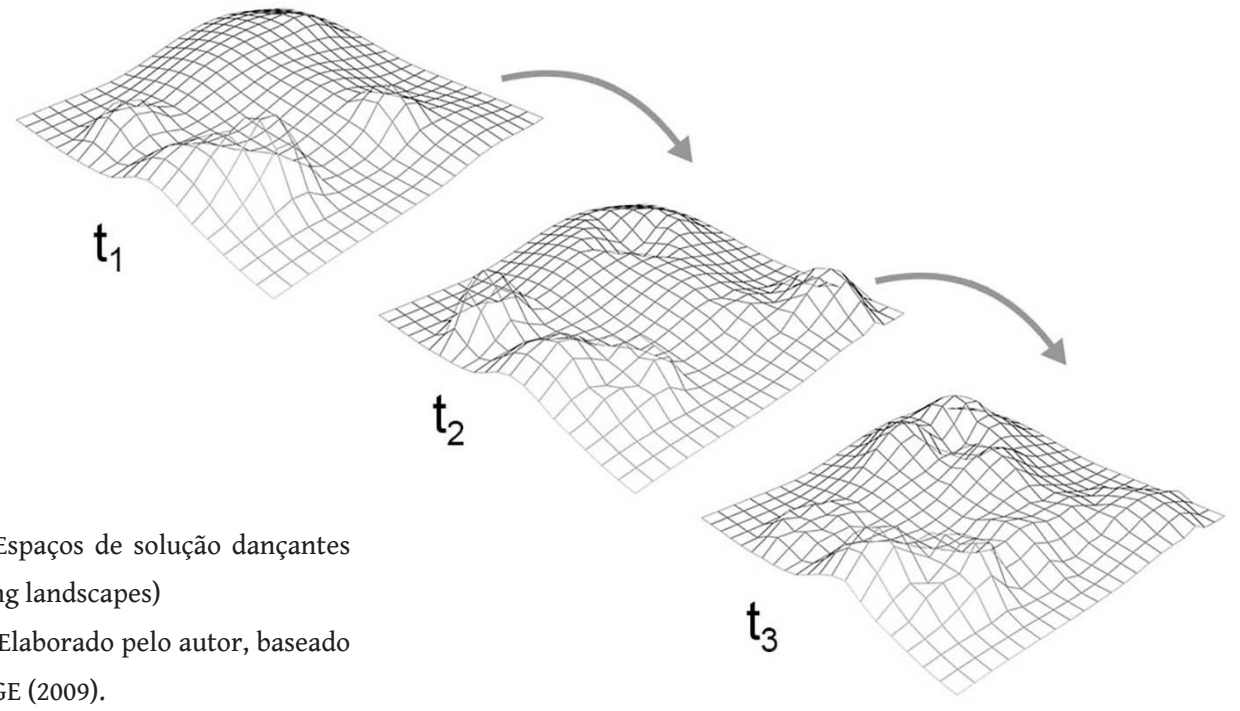


um pico no gráfico, mas, uma vez encontrado, ele é nosso! Se o problema permanecer o mesmo, ainda que muito complicado e com muitas interdependências, ele é bem comportado e se mantem sempre no mesmo lugar. Assim, se trata apenas de explorar todos os lugares desconhecidos do mapa até encontrar um bom pico e permanecer por lá.

Mas quando entram as concorrentes, a conformação do mapa muda à toda hora, pois elas também lutam por estar em bons picos, e fazem promoções, compram ou alugam aeronaves mais modernas e mais eficientes, planejam rotas mais econômicas e que aproveitam melhor a disponibilidade de pessoal. E a cada movimento de uma concorrente - digamos, uma promoção de preços - temos que nos mover em resposta. Assim, dá-se uma dança: para cada passo de um lado, ocorre um passo em resposta. E seguimos assim sempre. Assim, a complexidade acontece no tempo e varia as condições que envolvem e definem o problema.

A grande diferença que surge neste passo é que entra em cena a adaptação, isto é, o sistema adquire um comportamento em face do ambiente. $\mathrm{E}$ a partir do momento em que a adaptação entre em cena passamos a ter um problema complexo.

Existe uma frase corrente que diz que é inexplicável que o homem já tenha conseguido ir à Lua, mas não saiba ainda a cura para um simples resfriado. Talvez o motivo esteja exatamente no que foi exposto acima: o problema de ir à Lua é muitíssimo complicado, mas não é exatamente complexo: uma vez estabelecido, ele está lá, fixo sempre no mesmo lugar. Se lançarmos um foguete, a Lua não vai mudar de órbita para evitar o pouso. Ela está lá à nossa espera, em sua evolução cíclica, previsível. Já o resfriado pode ser causado por vários tipos de vírus, os quais evoluem a cada ciclo, e, portanto, se adaptam. Nós, em contrapartida, nos adaptamos em resposta em nosso sistema imunológico e nos medicamentos que usamos, e assim a dança começa. Um problema é de fundo mecânico, cíclico, o outro, sistêmico, orgânico e complexo.

Os sistemas em geral podem ter algumas características conhecidas, como a diversidade (que estabelece que as partes e suas relações são diferentes entre si), a conectividade (que estabelece que estas partes se conectam, ou seja, trocam algum tipo de dependência de estado ou informação) e interdependência (que estabelece que esta conectividade é de mão dupla). Mas só os sistemas complexos têm uma quarta característica, que é a adaptação. Ela estabelece que o fluxo de conectividade e interdependência são intensos o suficiente para fazer com que o sistema inteiro se mova.

Trocando em miúdos, enquanto tivermos apenas as três primeiras características dos sistemas - diversidade, conectividade e interdependência - teremos um espaço de solução enrugado e estático. Estes problemas não apresentam complexidade e são, de forma geral, de solução mais fácil. São estes problemas que estamos acostumados a resolver no campo do design. Projetar um aeroporto, um hospital ou uma usina nuclear mais segura 
são grandes desafios para arquitetos e engenheiros, mas são problemas com picos fixos. Tudo o que temos que fazer é encontrá-los. Isso pode não ser fácil, mas é factível, desde que haja recursos e tempo suficientes.

Mas quando passamos a ter adaptação das condições do problema, isto é, quando passamos a ter que reagir a um ambiente mutável, passamos a lidar com uma paisagem dançante. E é aí que temos, de fato, complexidade. E esta é a natureza dos problemas de complexidade massiva e de grande interdependência e potencial adaptativo. $O$ problema do trânsito nas grandes cidades, por exemplo, lida com uma infinidade de agentes se movimentando simultaneamente, tomando decisões em tempo real, fazendo mudar o quadro de referência a cada minuto, constituindo-se num exemplo que podemos ilustrar como um relevo dançante. Na verdade, uma infinidade de outros problemas que enfrentamos em nosso dia-a-dia também são de natureza complexa, e alguns sempre foram. 0 tráfego das grandes cidades não surgiu no século XXI. O que ocorre é que este tipo de problema é cada vez mais frequente. Vários problemas que antes eram simples, hoje apresentam comportamento complexo.

Um problema realmente complexo, muitas vezes não é sequer mapeável cognitivamente - ou seja, não é passível de ser modelado pela mente humana - e, além disso, ele muda. Então para que disponibilizar recursos e tempo para uma equipe no tratamento de um problema complexo, se quando a solução vier, o problema já será outro, talvez completamente diferente?

Alan Moore dedicou um livro à questão da não-linearidade e, portanto, da imprevisibilidade dos nossos tempos.

\footnotetext{
Agora é o momento em que precisamos de uma forma de avaliar o que vem a seguir, quando encaramos um mundo que passou, em um curto período de tempo, de linear (simples) para complexo e não-linear (caótico). Quando nos movemos em um mundo que é inerentemente mais complexo, o resultado é contundente, seus efeitos desorientadores no rodeiam e nossas reações, tanto individuais quanto nas organizações, resultam em reflexos e perspectivas que podem ser perigosamente corrosivas e inadequadas. (MOORE, 2011)5
}

Este tipo de cenário não dá mais chance aos métodos projetuais tradicionais, que contam com um projetista que consegue compreender os problemas que enfrenta em sua completude, simplesmente porque os problemas mudaram sua complexidade. A seguir vamos estabelecer o que, exatamente queremos dizer com essa afirmação. 


\section{Problemas mal comportados versus modelos mentais}

Iremos, brevemente, localizar os comportamentos dos sistemas complexos dentro do contexto da teoria dos sistemas antes de prosseguir. Stephen Wolfram, matemático e físico britânico, elaborou uma classificação de sistemas em quatro classes quando montou um modelo de trabalho de seus autômatos celulares na obra A New Kind of Science (2002).

A primeira classe de sistemas é a de comportamentos estáveis e simples, que envolvem poucos elementos que são conectados e interdependentes. Estes elementos tendem a interagir de poucas formas, resultando em um mesmo estado final. 0 nosso gráfico de relevo resultante do problema da pá é um caso de comportamento simples.

A segunda classe é de comportamentos cíclicos, com um pouco mais de elementos também conectados e interdependentes, mas que exibem um comportamento cíclico e, portanto, previsível, como um relógio mecânico. Este é o caso do problema da companhia aérea antes de ter concorrentes.

A terceira classe é a de comportamentos caóticos, que tendem a ser imprevisíveis e que consistem em muitíssimos elementos que podem interagir e mudar de padrão constantemente. É o comportamento exibido nos sistemas climáticos, que têm milhões ou bilhões de elementos que interagem para gerar um estado. Mas este estado está sempre evoluindo de formas muito difíceis de medir justamente em função da quantidade de elementos constituintes e da densidade de interações. Este é o estado retratado na imagem do efeito borboleta, termo criado pelo cientista americano Edward Lorenz que estabeleceu as bases matemáticas para sistemas numéricos de previsão do tempo. Segundo este princípio uma causa muito pequena pode evoluir para efeitos gigantescos, justamente em função dos padrões que surgem durante a evolução do sistema. Este gráfico seria um relevo que dança freneticamente e que talvez desafie as leis da física, ou seja, onde picos elevados estão flutuando no ar, e entre um pico e outro hajam grandes espaços vazios, ou dois picos ocupando o mesmo espaço.

E a quarta classe, que se constitui em comportamentos complexos, que não são tão imprevisíveis quanto os caóticos, mas nem tão previsíveis quanto os sistemas cíclicos. São na verdade um estado intermediário entre estas duas classes. As estruturas internas dos sistemas complexos são, via de regra, muito simples, mas se combinam de forma extremamente intrincada e estabelecem relações de interdependência entre si, o que resulta numa estrutura geral muito complexa. Este é o caso da companhia aérea que é obrigada a dançar por causa da concorrência. 


\section{I pur si muove}

Os sistemas, no entanto, podem mudar de classe dependendo da evolução de suas qualidades, ou seja, na verdade, um sistema pode passar de cíclico a complexo, e depois passar a caótico, e voltar a exibir comportamento cíclico mais adiante. Quando nos referimos a um sistema complexo estamos, na verdade, nos referindo a um sistema que, num dado momento, exibe este tipo de comportamento, mas que, dependendo de alguns fatores, pode mudar. E este é mais um motivo que justifica a dificuldade em fazer um modelo mental destes problemas. Os problemas urbanos, por exemplo, são exemplos deste fenômeno, e a arquiteta e professora da Universidade de Lucerna para Ciências Aplicadas e Artes Ulrike Sturm expressou esta relação, ao falar de projetos urbanos, quando participou do Metadesign Colloquium Attainable Utopias.

\footnotetext{
A história do planejamento urbano no século XX revela a firme crença de seus protagonistas de que projetar a cidade também era projetar a sociedade. No entanto, os produtos deste tipo de planejamento se provaram desastres completos. Isto ocorreu, como quero argumentar, devido à ideia de uma mente mestre (mastermind) que têm todas as informações necessárias que não só atendem às necessidades dos futuros usuários, mas também dão forma às pessoas para as quais o projeto foi feito. (...) Derivado originariamente de inspiração religiosa, este conceito de um projeto de um mestre não está mais apto para servir de diretriz ao projeto de cidades supercomplexas e suas comunidades (STURM, 2005) ${ }^{6}$
}

Quando achamos que entendemos como o tráfego da cidade se comporta e começamos a nos sentir confiantes a ponto de montar um modelo mental ou computacional, descobrimos que o que entendemos é o modelo, e não o problema, pois ele mudou. E num dado momento entendemos que este sistema não é passível de modelagem. É um problema mal comportado, irrequieto, flutuante, móvel. É o que os especialistas chamam de wicked problem (em português, um problema perverso).

Donella Meadows, pesquisadora da área da dinâmica dos sistemas, menciona a percepção de seu mentor Jay Wright Forrester, ao afirmar que é temerário atuar sobre um sistema que não é transparente à cognição.

Contraintuitivo: é a palavra que Forrester usava para descrever os sistemas complexos. Os pontos de alavancagem são frequentemente não intuitivos. Ou quando são, nós frequentemente os usamos ao contrário, sistematicamente piorando os problemas que estamos tentando resolver. (MEADOWS, 2008, p. 146) 
Dessa forma, é extremamente difícil ter certeza de que, ao atacar o problema a partir de uma certa perspectiva, iremos obter o resultado esperado. As relações não são lineares e fáceis de prever, elas se movem inesperadamente e, quando nos damos conta, estamos lidando novamente com um modelo parcial e ultrapassado e não com o problema real.

\section{Impor ou influenciar?}

Mas, aparentemente, nem tudo está perdido. Os mesmos pesquisadores que anunciam as dificuldades de atacar os problemas complexos de forma direta, como Meadows, também concordam que os problemas complexos podem ser influenciados de forma indireta. Isto quer dizer que, se temos de abrir mão de uma abordagem projetual que impõe uma solução a um problema que talvez seja demasiadamente elusivo, podemos criar regras de comportamento que façam com que o problema se desloque a posições mais favoráveis. Problemas complexos podem se tornar cíclicos e se tornarem mais acessíveis.

Pesquisadores do processo de design como Greg Van Alstyne, Robert Logan, ambos da Universidade de Toronto, e a pesquisadora Elisa Giaccardi da Delft University of Technology (TU Delft) afirmam que o processo projetual pode usar de métodos e técnicas que eles chamam de metadesign para atingir problemas de alta complexidade.

Alstyne e Logan recomendam, em um artigo de 2007, usar os subprodutos dos sistemas complexos, nomeadamente os processos emergentes, como uma forma de atuar sobre estes sistemas. A ideia é usar a ordem proveniente de processos emergentes para indicar outras ordenações no campo projetual.

Assim, a criação de uma comunidade no entorno do problema serviria para provocar organizações espontâneas que guiariam o processo projetual. Os dois processos geram ordem, o projeto e a emergência, mas o primeiro tem uma estrutura impositiva, top-down, o segundo uma estrutura espontânea e bottom-up.

[...] o design é caracteristicamente um processo top-down, no qual o designer, trabalhando como o artista, começa com os efeitos e resultados e procura as causas que trarão estes à tona. Em contraste, emergência é um processo bottom-up, no qual os componentes do sistema se auto-organizam através de suas interações uns com os outros sem uma intenção singular e abarcante. $\mathrm{O}$ designer está tipicamente no controle do processo de design, enquanto na emergência os componentes do sistema não controlam o resultado - eles simplesmente o influenciam através de suas interações mútuas. (ALSTYNE e LOGAN, 2007, p. 12) ${ }^{8}$ 
Nesta tabela, uma comparação entre os dois processos.

\begin{tabular}{ll}
\hline Design & Emergência \\
\hline $\begin{array}{l}\text { Caracterizado pela intencionali- } \\
\text { dade do designer humano }\end{array}$ & $\begin{array}{l}\text { Caracterizado pela autonomia de múl- } \\
\text { tiplos agentes ou componentes }\end{array}$ \\
\hline Top-down & Bottom-up \\
\hline Controlar & Influenciar \\
\hline & \\
\hline
\end{tabular}

Quadro 1. Tabela de semelhanças e oposições entre o processo de design e os processos emergentes característicos dos sistemas complexos

Fonte: Adaptado de Alstyne e Logan (2007) ${ }^{9}$

Assim, para poder influenciar um sistema complexo, pode-se criar uma complexidade análoga, uma comunidade complexa o bastante, que faça com que a complexidade do problema seja espelhada por ela. Projetos de grande fôlego, como o sistema operacional Linux, conta com centenas de milhares de programadores espalhados pelo mundo que se reúnem em forma de comunidade online para dar conta do desafio de criar o sistema operacional mais comum entre os servidores web.

Mas na medida em que delegarmos às comunidades massivas a função de lidar com estes problemas, o que acontece com o papel do designer?

\section{Amanhã seremos designers?}

Em várias situações, sobretudo no projeto de softwares e aplicativos online, os usuários são chamados a contribuir no seu direcionamento através de várias formas, sobretudo através do monitoramento do uso. Os exemplos são muitos e se estendem desde a famosa wikipedia até os softwares de desenvolvimento open source. A contribuição da comunidade é fundamental, seja ela de usuários que fazem críticas aos softwares ou de desenvolvedores que se comportam como um enxame auto-organizado. Tim O'Reilly, dirigente da O'Reilly Media Group e entusiasta do movimento open source, percebeu este fenômeno muito cedo. 
Usuários devem ser tratados como codesenvolvedores, como reflexo do desenvolvimento de práticas open source (mesmo que o software em questão for publicado somente sob licença open source). 0 dito open source "publique cedo, e publique frequentemente" de fato se transformou numa posição mais radical, o "beta perpétuo", no qual o produto é desenvolvido abertamente, com os novos recursos liberados mensal, semanal ou diariamente. Não é acidente que os serviços como Gmail, Google Maps, Flickr, del.icio.us and outros parecidos provavelmente ficarão com um logo "beta" por anos (O'REILLY, 2003) ${ }^{10}$

Mas não são todas as áreas de projeto que encaram esta relação com as comunidades de usuários como uma colaboração frutífera. Algumas áreas do design são mais abertas a estas interações e outras menos. A imagem do designer-artista, que é auto suficiente ainda é muito forte em nossa cultura e presente em nosso cotidiano, pelo menos em algumas áreas de atuação.

Assim, ficamos ainda com esta questão: será que, ao ser convocado a lidar com estas comunidades o designer vai ceder espaço tranquilamente? Vai conseguir lidar com esta perda de poder? E mais, será que ao conceder a estas comunidades o poder de coprojetar, vai ainda estar exercendo seu ofício da mesma forma? Poderemos chamar a este método projetual ainda de projeto, ou estaríamos falando de outra coisa?

[...] se a complexidade cresce, existem duas coisas que acho que devem crescer junto: de um lado, são as práticas colaborativas. De outro é a participação; mas isso significa que de um lado o designer perde o controle do processo de design. Então quanto mais o usuário está envolvido em interpretar, projetar e desenvolver soluções, menos os designers controlam isso [...]. Será que o designer está pronto para aceitar, para lidar com menos controle, ter menos controle sobre o processo de design e também sobre o resultado desse processo? (SANGIORGI, 2015) ${ }^{11}$

Estas questões ficam todas em suspenso, enquanto procuramos nosso rumo em meio a problemas de grande complexidade e a perda de controle projetual. Ao final desta grande mudança de paradigma -se é que podemos falar de um final - seremos outros, com outras funções dentro da profissão e também outros no contexto maior da sociedade. Provavelmente novas responsabilidades virão, com mais interlocução e mais ferramentas para compreensão de problemas e de representação de ideias. A única certeza que temos é a da permanente incerteza pois, como dissemos anteriormente, agora dançamos sobre areia movediça. 


\section{A era da complexidade no design}

Em outras épocas, os problemas levantados pela crescente complexidade já fizeram com que novos métodos de projeto fossem criados e outros sedimentados. O "design by drawing" - ou seja, o ato de representar o projeto através de um desenho ao invés de simplesmente atuar no problema diretamente - embora já existisse, se tornou o principal padrão de atuação dos designers para dar conta da complexidade crescente das máquinas geradas pela revolução industrial. A complexidade envolvida em uma máquina com várias partes e que se movimentam de forma interdependente é mais facilmente domada através da representação gráfica precisa e em escala. Este fato é largamente documentado por John Chris Jones nos capítulos iniciais do Design Methods (JONES, 1992). Da mesma forma, o uso de desenhos representados em escala permitiu ao projetista trazer para seu controle o planejamento de objetos de grandes dimensões e complexidade, como o maquinário pesado e grandes navios. Em resumo, a época das grandes máquinas da revolução industrial necessitou de um tipo de projeto próprio, e de instrumentos para estes projetos.

Hoje, no momento em que nos vemos em contato com problemas que envolvem dezenas ou milhares de partes, de centenas de milhares de usuários que interagem entre si e sistemas com dezenas de milhares de linhas de código, muitas vezes desenvolvidos por milhares de pessoas espalhadas pelo globo, acredito que precisamos de novos métodos de design.

Máquinas cíclicas, como as criadas pela revolução industrial (motores, turbinas, dínamos) eram compatíveis com os métodos tradicionais de projeto, como o "design by drawing" citado por Jones, e concebidas por um único projetista, pois sua complexidade cíclica era absolutamente previsível e facilmente dominada por ele e representada através de desenhos. Mas muitas "máquinas" de hoje são de outra natureza, pois não são mais cíclicas, são complexas. São constituídas de ciclos montados em outros ciclos, pouco previsíveis. A compreensão de suas interdependências não é trivial. E mesmo se fosse provavelmente não poderíamos modificá-las através de um projeto, já que, como expusemos há pouco, seu contexto é variável. Os problemas imersos em complexidade são multifacetados e envolvem vários aspectos da vida. Sua complexidade não é facilmente dominada por um indivíduo ou mesmo um grupo de especialistas. Seu caráter complexo precisa de uma abordagem nova, que privilegie a articulação de expectativas e tente influenciar o sistema ao invés de se impor a ele.

As metáforas da vida contemporânea estão migrando da máquina para o organismo, dos sistemas cíclicos para os complexos. Os métodos projetuais não podem se dar ao luxo de permanecer onde estão. 
1 Todas as traduções das citações usadas neste trabalho foram feitas pelo autor do artigo. No original se lê: The Design Methods movement emerged in the 1950s as it was increasingly realized that creative individuals working in isolation were no longer able to solve the bigger and more complex problems facing them in the post-Second World War period. This was reflected in the curricula of progressive institutions such as the Hochschule für Gestaltung at Ulm, where design was set alongside other disciplines such as anthropology, sociology, behavioural psychology, and recent cultural history and theory.

2 The writings of design theorists imply that the traditional method of design-by-drawing is too simple for the growing complexity of the man-made world. This belief is widely held and may not require any further justification. 3 To imagine that anyone closed group could solve the problems we confront today is folly.

4 Human intuition, which arguably has been shaped by biological evolution to deal with the environment of hunters and gatherers, is showing its limits in a world whose dynamics are getting more complex by the minute. 5 Now is the time when we need a way of evaluating of what comes next, when we face a world that has gone in a very short period of time from seemingly linear (simple) to complex and non-linear (chaotic). When we move into a world that is inherently more complex, the result is concussive, its disorientating effects surround us, and our responses either individually or at an organisational level result in reflexes and perspectives that can be dangerously corrosive or inappropriate.

6 The history of urban planning in the 20th century reveals the strong belief of its protagonists that designing cities also means designing society. Yet the products of this type of planning have in many respects proved complete failures. This is, as I want to argue, partly due to the idea of a mastermind who possesses all necessary information for creating objects that do not only meet all the needs of future users, but also shape the people the design is made for. (...) Originally derived from religious inspiration this concept of a master's design is no longer apt to serve as guideline for designing super-complex systems as cities and their communities.

7 Counterintuitive: that's Forrester's word to describe complex systems. Leverage points frequently are not intuitive. Or if they are, we too often use them backward, systematically worsening whatever problems we are trying to solve.

8 [...] design is characteristically a top-down process in which the designer, working as an artist does, begins with the desired effects and outcomes and looks for causes that will bring these about. In contrast, emergence is a bottom-up process in which the components of the system self-organize through their interactions with each other without a singular, overarching intention. The designer is typically in control of the design process, whereas in emergence the components of the system do not control the outcome - they merely influence it through their mutual interactions with each other.

9 Design/Emergence / Characterized by the intentionality of the human designer/Characterized by the autonomy of massively multiple agents or components | Top-down/Bottom-up | Controlling/Influencing

Setting constraints/Exploring and testing constraints

10 Users must be treated as co-developers, in a reflection of open source development practices (even if the software in question is unlikely to be released under an open source license.) The open source dictum, "release early and release often" in fact has morphed into an even more radical position, "the perpetual beta," in which the product is developed in the open, with new features slipstreamed in on a monthly, weekly, or even daily basis. It's no accident that services such as Gmail, Google Maps, Flickr, del.icio.us, and the like may be expected to bear a "Beta" logo for years at a time.

11 [...] if complexity grows, there are two things that I see that should grow as well: on one side is collaborative practices. On the other side is the participation; but this means that on one side the designer loses control on the design process. So the more the user is involved in interpreting, designing and developing the solutions, the less designers control this. [... Is the designer ready to accept, to deal with less control, have less control on the design process and also on the design output?

DATJournal v. 5 n.4 2020 


\section{Referências}

ALSTYNE, Greg Van; LOGAN, Robert K. Designing for emergence and innovation: Redesigning design. Artifact: Journal of Design Practice, v. 1, n. 2, p. 120-129, 2007. BERTALANFFY, Ludwig von. Teoria geral dos sistemas. São Paulo: Vozes, 2016. CIPINIUK, Alberto; PORTINARI Denise. Sobre métodos de design. In: Design Método. Rio de Janeiro: Ed. PUC Rio, 2006.

JONES, John C. Design Methods. New York: John Wiley \& Sons, 1992.

MAU, Bruce. Massive Change. London: Phaidon, 2004.

MEADOWS, Donella. Thinking in systems: a primer. Vermont: Chelsea Green Publishing, 2008.

MILLER, Peter. The smart swarm. How understanding flocks, schools and colonies can make us better in communicating, decision making and getting things done. New York: Gildan Media, 2011.

MOORE, Alan. No straight lines. Cambridge: Bloodstone Books, 2011.

PAGE, Scott. Understanding Complexity. Chantilly: The Great Courses, 2009.

SANGIORGI, Daniela. Service design and systemic thinking. In: Colloquium on Metadesign, London: 2007. Disponível em: <http://attainable-utopias.org/tiki/DanielaSangiorgiMovie>. Acesso em: 03 ago 2020.

STURM, Ulrike. From Master-Design to Meta-Design. In: Colloquium on Metadesign, London: 2005. Disponível em <http://attainable-utopias.org/tiki/tiki-download_file.php?fileId=140>. Acesso em 06 ago 2020.

WOLFRAM, Stephen. A new kind of science. Champaign: Wolfram Media, 2002.

WOODHAM, Jonathan. Oxford Dictionary of Modern Design. New York: Oxford University Press, 2006. 